\title{
Comment on: "Characterization of Microroughness Parameters in Titanium Nitride Thin Films Grown by DC Magnetron Sputtering" [J Fusion Energ DOI 10.1007/s10894-012-9510-z]
}

\author{
Shahram Solaymani $\cdot$ Atefeh Ghaderi · \\ Negin Beryani Nezafat
}

Published online: 28 March 2012

(C) Springer Science+Business Media, LLC 2012

\begin{abstract}
In recent article [Ali Gelali. Azin Ahmadpourian. Reza Bavadi. M. R. Hantehzadeh. Arman Ahmadpourian. J Fusion Energ DOI 10.1007/s10894-012-9510-z], Ali Geleli et al. studied the PSD and RMS Roughness parameters in Titanium Nitride thin films by AFM data and used the computed fractal dimension value of micrographs to describe the surface morphology of thin films. Here, the correct form of equations and relationship between PSD and RMS will be discussed.
\end{abstract}

Keywords Power Spectral Density · Root Mean Square · Atomic Force Microscopy

According to Ali Gelali et al. [1], AFM image analysis section, in line 5 is written RRMS which is not correct and it should be written $R_{r m s}$. Also, in line 10 the second $h_{i}$ related to Eq. (1) should be replaced by $<\mathrm{h}>$ since they talk about the mean height [2]. Besides, in page 3, line 5, $\Delta \mathrm{L}=\mathrm{N} / \mathrm{L}$ can not dimensionally be correct relation and the proper Equation is $\Delta \mathrm{L}=\mathrm{L} / \mathrm{N}$ [3] and more, as can be seen in [4] the correct form of Eq. 5 is $D_{f}=4+\gamma / 2$.

Forth page, second column, fifth line, authors speak about "the PSDs of both the films" whereas, there samples were investigated and is not clear which two of the samples are noteworthy. Afterwards authors clime that the low frequency components of the PSD spectrum represent the aggregates [1] however, according to AFM images particle's aggregation is only can be seen in sample 3 and not for sample 1 and 2 .

On the whole, PSD function is used because it can show changes better than RMS Roughness providing RMS changes will be little as can be seen in introduction of [1]. By considering this issue, one can see from Table 2 [1] that change between RMS is high which is not proper to use PSD function and make some errors and of course is against the introduction and conclusion.

\section{References}

1. A. Gelali, A. Ahmadpourian, R. Bavadi, M.R. Hantehzadeh. Arman Ahmadpourian. J. Fusion Energ. doi:10.1007/s10894-0129510-z

2. T. Jiang, N. Hall, A. Ho, S. Morin, Thin Solid Films 471, 76-85 (2005)

3. T. Itoh, N. Yamauchi, Appl. Surf. Sci. 253, 6196-6202 (2007)

4. Y. Wang, K.-W. Xu, Thin Solid Films 468, 310-315 (2004)

S. Solaymani $(\bowtie) \cdot$ A. Ghaderi

Young Researchers Club, Islamic Azad University,

Kermanshah Branch, Kermanshah, Iran

e-mail: shahram22s2000@yahoo.com

N. B. Nezafat

Plasma Physics Research Center, Science and Research Branch,

Islamic Azad University, Tehran, Iran 